\title{
Knee osteoarthritis: pathophysiology and current treatment modalities
}

\author{
Juan C Mora' \\ Rene Przkoral \\ Yenisel Cruz-Almeida ${ }^{2}$ \\ 'Department of Anesthesiology, \\ Division of Pain Medicine, University \\ of Florida, Gainesville, FL, USA; \\ ${ }^{2}$ Department of Aging and Geriatric \\ Research, Institute on Aging, Pain \\ Research and Intervention Center \\ of Excellence, University of Florida, \\ Gainesville, FL, USA
}

This article was published in the following Dove Press journal: Journal of Pain Research

\begin{abstract}
For decades, multiple attempts to fully understand knee osteoarthritis pathophysiology and natural history have been attempted. Despite the extensive amount of research regarding this topic, there are still marked controversies. This multifactorial condition gets influenced by local, systemic, and external factors and its progression and/or response to treatments widely varies from patient to patient. Multiple therapies have been studied in the past, low impact physical activity seems to be supported by all the current medical societies while other interventions have shown conflicting findings. Newer therapies and routes of administration are under investigation and some of them have shown promising preliminary reports. This review intends to give an overview of the current knowledge of pathophysiology and non-surgical therapies available for knee osteoarthritis.
\end{abstract}

Keywords: knee osteoarthritis, cartilage degeneration, non-inflammatory arthritis, intra-articular injections, corticosteroids

\section{Introduction}

Osteoarthritis (OA) is the most common form of arthritis and one of the leading causes of disability. This degenerative and progressive joint disease affects around 250 million people worldwide ${ }^{2}$ and more than 27 million people in the United States. ${ }^{3,4}$ Elderly (approximately $35 \%$ of patients over 65 years old) females, patients with obesity and African Americans are the population with the highest risk of developing OA. ${ }^{5,6}$ Given the trend of the population to live longer and the progressive increment of obesity in our country, the number of affected patients most likely will substantially increase within the upcoming years. This is concerning given the functional impairment and disability associated with this condition and its negative toll on the social and economic aspects of our society.

This review will discuss the current evidence regarding the pathophysiology of knee osteoarthritis, the current recommendations of treatment, with a special focus on intervention modalities including intra-articular steroids and the new extended-release (ER) presentations of these components.

\section{Knee osteoarthritis}

The knee is the largest synovial joint in humans, it is composed by osseous structures (distal femur, proximal tibia, and patella), cartilage (meniscus and hyaline cartilage), ligaments and a synovial membrane. The latter is in charge of the production of the synovial fluid, which provides lubrication and nutrients to the avascular cartilage. ${ }^{6}$
Correspondence: Juan C Mora Department of Anesthesiology, Division of Pain Medicine, University of Florida, PO Box 100254, Room 2036, Gainesville, FL 32610-0254, USA

$\mathrm{Tel}+\mathrm{I} 3522650077$

$\mathrm{Fax}+\mathrm{I} 3522656922$

Email jmora@anest.ufl.edu 
Unfortunately, given the high use and stress of this joint, it is a frequent site for painful conditions including OA. ${ }^{7}$

OA is classified into two groups according to its etiology: primary (idiopathic or non-traumatic) and secondary (usually due to trauma or mechanical misalignment). The severity of the disease can also be graded according to the radiographical findings by the Kellgren-Lawrence (KL) system described in $1957 .{ }^{8}$ It was believed that OA was exclusively a degenerative disease of the cartilage, however, latest evidence has proven that $\mathrm{OA}$ is a multifactorial entity, involving multiple causative factors like trauma, mechanical forces, inflammation, biochemical reactions, and metabolic derangements. ${ }^{9}$ It is also known that the cartilaginous tissue is not the only one involved. Given its lack of vasculature and innervation, the cartilage, by itself is not capable of producing inflammation or pain at least on early stages of the disease. Hence, the source of pain is mainly derived from changes to the non-cartilaginous components of the joint, like the joint capsule, synovium, subchondral bone, ligaments, and periarticular muscles. ${ }^{6,9}$ As the disease advances, these structures are affected and changes including bone remodeling, osteophyte formation, weakening of periarticular muscles, laxity of ligaments, and synovial effusion can become evident. ${ }^{10}$

The role of inflammation is not well-understood and there is an ongoing debate to determine if the inflammatory reaction triggers the OA changes, or instead, the inflammation is secondary to the OA changes. ${ }^{9}$ Different from inflammatory arthritis, inflammation in OA is chronic and low-grade inflammation, involving mainly innate immune mechanisms. Synovitis (infiltration of inflammatory cells into the synovium) is a common finding of OA and it can be present in early stages of the disease but is more prevalent towards the more advanced stages and can be related with severity. ${ }^{1}$ In OA, the synovial fluid has been found to contain multiple inflammatory mediators including plasma proteins (C-reactive protein, proposed as a marker for development and progression of OA), prostaglandins (PGE2), leukotrienes (LKB4), cytokines (TNF, IL1 $\beta$, IL6, IL15, IL17, IL18, IL21), growth factors (TGF $\beta$, FGFs, VEGF, NGF), nitric oxide, and complement components. ${ }^{1,11}$ Locally, all of these components can induce matrix metalloproteinases and other hydrolytic enzymes (including cyclooxygenase two and prostaglandin E) resulting in cartilage breakdown secondary to proteoglycan and collagen destruction. ${ }^{12}$

White blood cells are also involved, extracellular matrix breakdown releases certain molecules (damage-associated molecular patterns) that are recognized by the innate immune cells (macrophages and mast cells), usually as a protective mechanism. However, this prolonged and dysregulated degree of inflammation can lead to tissue destruction. ${ }^{1}$ In animal studies, macrophages have been found to be involved in the development of osteophytes that are a pathological feature of OA. ${ }^{1}$

The body also has protective molecular mechanisms including various growth factors (insulin-like, plateletderived, fibroblast 18, and transforming growth factor B), which, unfortunately, are altered in patients with knee OA and may become harmful to the joint. ${ }^{1,11}$

\section{Treatment}

$\mathrm{OA}$ is a progressive and degenerative condition, with unlikely regression and restoration of damaged structures. Thus, current management modalities are targeted towards symptom control unless the degree of severity dictates the necessity of surgical intervention with joint replacement. ${ }^{1}$

Currently, different guidelines have been developed by multiple academic and professional societies to standardize and recommend the available treatment options (Table 1). Among these, we can find the Osteoarthritis Research Society International (OARSI), ${ }^{13}$ American College of Rheumatology $(\mathrm{ACR})^{14}$ and American Academy of Orthopedic Surgeons $(\mathrm{AAOS})^{15}$ publications.

\section{Non-pharmacological management}

The aim of the management of OA is to control the painful signals originated from these joints, but even more, to improve functionality and quality of life. Non-pharmacological therapies should always be attempted as the first line of treatment for knee OA..$^{3,6,13-15}$

Inactivity and disuse are deleterious for the health of the knee joint, the absence of mechanical stimulation induces a more rapid cartilage degeneration due to cartilage softening/ thinning, decrease of glycosaminoglycan content, impaired joint mechanics and flexibility. ${ }^{16,17}$ Light-to-moderate physical activity provides multiple benefits to this patient population, besides the mechanical and functional improvements, they also offer a risk reduction of diabetes, cardiovascular events, falls, disability, and an improvement in mood, and self-efficacy. ${ }^{16,18}$

Exercise routines should be tailored to every patient's needs/tolerance and preferences, high impact activities should be avoided, and long-term adherence should be maximized to increase success. ${ }^{18,19}$ There are different exercise modalities shown to have a favorable effect on patients with knee OA (Table 2), routines should be performed three times a week, and to assess response, the patient should complete at least 12 sessions. $^{6}$ 
Table I Knee osteoarthritis management recommendations from societies

\begin{tabular}{|l|l|l|l|}
\hline Societies recommendations & OARSI & ACR & AAOS \\
\hline Treatment & Appropriate & Strong recommendation & Strong recommendation \\
\hline Exercise (land and water based) & Conditional recommendation & Inconclusive \\
\hline $\begin{array}{l}\text { Transcutaneous electrical nerve } \\
\text { stimulation (TENS) }\end{array}$ & Apcertain & Strong recommendation & Moderate recommendation \\
\hline Weight control & $\begin{array}{l}\text { Not appropriate for disease } \\
\text { modification, Uncertain }\end{array}$ & Recommended against use & Recommended against use \\
\hline Chondroitin or Glucosamine & Without comorbidities: appropriate & Conditional recommendation & Inconclusive \\
\hline Acetaminophen & Appropriate & No recommendation & No recommendation \\
\hline Duloxetine & $\begin{array}{l}\text { Without comorbidities: appropriate } \\
\text { With comorbidities: not appropriate }\end{array}$ & Conditional recommendation & Strong recommendation \\
\hline Oral NSAIDs & Appropriate & Conditional recommendation & Strong recommendation \\
\hline Topical NSAIDs & Uncertain & No recommendation & Recommended only tramadol \\
\hline Opioids & Appropriate & Conditional recommendation & Inconclusive \\
\hline Intra-articular corticosteroids & Uncertain & No recommendation & Recommended against use \\
\hline Intra-articular viscosupplementation &
\end{tabular}

Note: Data from these studies. ${ }^{13-15}$

Abbreviations: OARSI, Osteoarthritis Research Society International; ACR, American College of Rheumatology; AAOS, American Academy of Orthopedic Surgeons; TENS, transcutaneous electrical nerve stimulation; NSAIDs, non steroidal antiinflamatory drug.

Table 2 Different exercise modalities for knee OA

\begin{tabular}{|c|c|c|c|}
\hline \multirow[t]{2}{*}{ Aerobic/endurance } & Exercise modalities & \multirow[t]{2}{*}{ Balance/proprioceptive } & \multirow[t]{2}{*}{ Stretching } \\
\hline & Resistance/strength training & & \\
\hline $\begin{array}{l}\text { Include activities like walking, } \\
\text { climbing stairs, and cycling. They } \\
\text { can decrease joint tenderness } \\
\text { while improving functional status } \\
\text { and respiratory capacity. Cycling } \\
\text { is especially attractive to patients } \\
\text { given the low impact profile. } .^{16,18} \\
\text { One study showed a reduction of } \\
10-12 \% \text { on the physical disability } \\
\text { and the knee pain questionnaires. }{ }^{16}\end{array}$ & $\begin{array}{l}\text { Isometric, isotonic, isokinetic, } \\
\text { and dynamic modalities have been } \\
\text { studied. Most of them targeting } \\
\text { quadriceps, hip abductors, } \\
\text { hamstrings, and calf muscles. They } \\
\text { improve strength, physical function, } \\
\text { and pain levels, with similar efficacy } \\
\text { and outcomes than aerobic } \\
\text { exercises. }\end{array}$ & $\begin{array}{l}\text { This includes modalities such as } \\
\text { Tai Chi, using slow and gentle } \\
\text { movements to adopt different } \\
\text { weight baring postures while using } \\
\text { breathing techniques. }\end{array}$ & $\begin{array}{l}\text { This group will specifically } \\
\text { help with patient's range of } \\
\text { motion and flexibility. }\end{array}$ \\
\hline
\end{tabular}

Aquatic (water-based) therapies provide an alternative to patients who are hesitant to start land-based exercises, given the lesser joint impact. Some patients can better tolerate aquatic therapy and decrease the exacerbation of symptoms (sometimes experienced when starting weight bearing routines). Some physicians use this therapy as a bridge to get to land-based modalities once the patient has lost the fear of moving. ${ }^{16,17}$

Weight management plays an important role in symptom management, and it has been noted that the benefit of exercise is potentiated by the reduction of weight. ${ }^{16}$ Obesity can predispose patients to suffer from knee OA, it has deleterious molecular and mechanical effects. The adipose tissue itself is a source of inflammatory factors. The cytokines adipokine, IL6, TNF alfa, and C-reactive protein are elevated in the plasma of obese patients and have been associated with alteration of cartilage homeostasis and degeneration. ${ }^{1,9}$ During ambulation, the knee joint has to support $3-5$ times the body weight, hence small changes in weight represent the high variation of forces to the joint. ${ }^{20}$ Regardless of the used method (bariatric surgery vs lifestyles modifications), there is around $10 \%$ risk reduction of knee OA per kilogram of bodyweight decreased (same proportion applies in the opposite direction for the increase in weight). ${ }^{21}$ These findings were also noted in "The Framingham study", a weight loss of 12 $\mathrm{lb}$ resulted in a $50 \%$ risk reduction for knee OA..$^{22}$ Not only the total weight reduction is important, but studies have also taken into account the changes in body fat percentage; each point reduction represents a $28 \%$ increase in function and a 9.4\% improvement in the Western Ontario and McMaster Universities Osteoarthritis Index (WOMAC) score. ${ }^{23}$

Regarding other non-pharmacological interventions, patients might benefit from thermal modalities, but there is insufficient evidence to recommend the use of transcutaneous electrical nerve stimulation (TENS) or therapeutic ultrasound. ${ }^{3}$ 


\section{Pharmacological management}

The vast majority of OA patients are elderly and most of them will have multiple comorbidities. Hence, special attention should be paid to the possible interactions and adverse effects that systemic medications can induce in this population. Historically, cyclooxygenase inhibitors (acetaminophen and NSAIDs) have been the most commonly used medications. But given the gastrointestinal, renal, cardiac, and hematological adverse effects of these medications, their long-term use is limited. Acetaminophen has shown to be inferior to NSAIDs and not superior to placebo for pain control, leading to some guidelines to abstain to recommend it as an effective medical management strategy for moderate-to-severe OA. ${ }^{15}$ Topical NSAIDs have shown to be safer, with a comparable, or slightly inferior efficacy than systemic NSAIDs. ${ }^{13,24}$ On short follow-up studies, they have shown to be superior to placebo in controlling pain during the first week of treatment but failed to prove benefit after 2 weeks. ${ }^{24}$

Recently, more and more awareness has been raised regarding the consequences of the chronic use of opioids. Studies also keep providing evidence that opioids are not superior to NSAIDs to improve OA pain or WOMAC scores, and the risks of their use, clearly outweigh the benefits. ${ }^{25,26}$ If a patient is refractory to other treatments and the use of an opioid is considered, Tramadol, a serotonin and norepinephrine reuptake inhibitor with weak $\mu$ opioid receptor agonist properties, has shown some benefit in the treatment of severe and moderate OA. This medication, compared to other opioids, has slightly less risk for abuse potential and respiratory depression..$^{27,28}$

Duloxetine is a serotonin and norepinephrine reuptake inhibitor approved by the US Food and Drug Administration (FDA) for treatment of diabetic peripheral neuropathy and fibromyalgia. Recent studies have revealed that when used for more than 10 weeks, this medication is better than placebo controlling pain and improving function in patients with OA..$^{29,30}$

\section{Interventional management}

Multiple substances delivered via intra-articular (IA) injections have been explored in the past. The idea behind this is that local treatments will have less systemic adverse effects and depositing the medication inside the joint will have a more direct effect. Studies have shown that in general IA therapies are more effective than NSAIDs and other systemic pharmacologic treatments, but they also disclosed that a percentage of that benefit might be secondary to IA placebo effect. ${ }^{2}$

\section{Corticoid injections}

Corticoids (CS), elicit their immunosuppressive and antiinflammatory effects by acting directly on nuclear receptors, interrupting the inflammatory cascade at multiple levels. They decrease the action and production of IL-1, leukotrienes, prostaglandins, and metalloproteinases ${ }^{9,11}$ and it is believed that these are some of the mechanisms of pain relief and increase joint mobility in knee OA.

Currently, the available FDA approved Immediate Release (IR) corticosteroids for IA usage are: Methylprednisolone Acetate (MA), Triamcinolone Acetate (TA), Triamcinolone Hexacetonide (TH), Betamethasone Acetate (BA), Betamethasone Sodium Phosphate (BSP), and Dexamethasone. ${ }^{9}$ Attempts to define which is the best option have been done in the past. Dosages equivalent or higher than $50 \mathrm{mg}$ of prednisone (equivalent to $40 \mathrm{mg}$ of TA and MA) seems to be linked to a longer pain relief effect of 12-24 weeks compared to the short pain relief of 2-4 weeks reported with lower dosages. ${ }^{31-36}$ There might be small differences between the approved IR corticosteroid preparations in terms of pain relief, but current evidence is equivocal. Yavuz et al mentioned that MA can provide superior pain relief in the first 6 weeks compared to the other corticosteroids used (TA, BDP), but all of them provide equivalent analgesia from week sixth to 12 th. ${ }^{36}$ Pyne et al also suggested that TA acts quicker and provides better pain relief for the first 3 weeks than MA, but the effect of the latter might not start immediately, thus it might provide better analgesia after the eighth week. ${ }^{37} \mathrm{~A}$ recent comparative study by Buyuk et al showed that both MA and TH were equally effective until week 24th with a peak of action by the second week, ${ }^{34}$ confirming similar findings by Lomonte et al. ${ }^{38}$

Multiple studies have tried to elucidate questions related to the use of IA CS, such as the specific mechanism of action, duration, CS of choice, indications, effect on cartilage structure/intra-articular space and adverse effects. Some of these studies have been highly variable in their design, showing contradictory results and hindering the creation of a strong consensus. This is reflected in the different association guidelines, the OARSI and ACR guidelines support their use, ${ }^{13,14}$ while the AAOS considered that the available evidence was inconclusive to recommend for or against them. ${ }^{15}$

Identifying the adequate candidates has been attempted in the past. Due to the anti-inflammatory effects, one of the first hypothesis believed that patients with knee effusion, synovitis, and increased thickness of the synovial membrane (showed by ultrasound) would be the group of patients to have 
the most benefit. A placebo-controlled trial showed promising correlation, ${ }^{31}$ but other studies did not show a strong association. ${ }^{39-41}$ Following this inflammatory trend, also cytological analyses of the synovial fluid were performed. Dieppe et al suggested that cell count was not related to the likelihood of response, ${ }^{42}$ but recently $\mathrm{McCabe}$ et al revealed that patients with high synovial white blood count (ranging from $251 / \mu \mathrm{L}$ to $1000 / \mu \mathrm{L}$ ) would have a better response than patients with lower counts. ${ }^{43}$

Other possible variables like the degree of knee tenderness, baseline pain, BMI, gender, and anxiety or depression, have failed to show reliable predictors of response. ${ }^{40,44-47}$

On the other hand, a low degree of radiographic changes on the KL system (0-1) seems to be related with a better response compared to patients with severe radiographical changes $(3-4) .{ }^{45}$

In the past, multiple techniques of IA knee injection have been described, including the anterolateral and anteromedial (performed with the knee flexed 60-90 degrees), as well as the mid-lateral and superolateral approaches (performed with the knee extended). ${ }^{35}$ Studies agree upon that using ultrasound guidance with the superolateral approach provides the best chance to inject the CS inside the knee joint accurately. On average using the ultrasound provides a $96.7 \%$ of accuracy, vs $81 \%$ with landmarks. Also, proper use of the ultrasound guidance can be reflected in better pain reduction, compared with other techniques. ${ }^{48-50}$

Although complications are rare (about 1 in 3000), ${ }^{11}$ they are still a concern for the use of this therapy. Facial flush and transient pot-injection flares are self-limited and can be seen within the first 3 days. ${ }^{35}$

A study comparing radiographical changes of repeated, every 3 months injections of $40 \mathrm{mg}$ of TA vs placebo for a 2-year period showed no difference, ${ }^{46}$ but a recent randomized controlled trial using MRI, found evidence of cartilage volume loss. ${ }^{51}$

Research regarding CS and knee cartilage integrity has also provided equivocal results, some studies suggest that there is no alteration in the cartilage structure, while others suggest that CS can promote chondrocyte destruction and increase the necessity for joint replacement. ${ }^{4,9,35,36,51}$ One of them found that the cartilage damage might be caused by oxidative stress which could be reduced by vitamin $\mathrm{C}$ supplement. ${ }^{52}$

A portion of the IA CS is absorbed systemically, with the possibility to produce hypoglycemia and transiently affect the hypothalamic-pituitary-adrenal (HPA) axis in up to $25 \%$ of the patients. ${ }^{34,53}$ Cortisol levels might decrease after injection, but they return to baseline after 1-4 weeks. ${ }^{34,53}$

\section{Extended-release triamcinolone acetonide}

In an attempt to prolong the pain relief benefit, and also to decrease adverse effects, avoiding the high peak plasma concentrations seen with the IR use, a molecule called FX006 was developed and was approved by the FDA by the end of 2017. FX006 has TA contained inside microspheres (from 20 to $100 \mu \mathrm{m}$ ). These microspheres are composed of Poly-Lactic-Co-glycolic Acid (PLGA), a biocompatible compound, which ultimately degrades into carbon dioxide and water. ${ }^{54-56}$

The first animal study using this medication was published in 2014 by Kumar et al. They found that there was a prolongation of analgesic effect, improvement in inflammation, pannus formation, cartilage damage and bone resorption, these without evidence of the HPA axis function. ${ }^{54}$

A phase- 2 double blind-multicenter study included 228 patients randomized to receive different concentrations of FX006 or $40 \mathrm{mg}$ of IR TA for 12 weeks. They found that the analgesic effect of FX006 compared to that of the IR was prolonged and amplified with an optimal dose of $40 \mathrm{mg}$. The analgesic effect was found to be superior at 2 through 12 weeks and significantly superior at 5-10 weeks. Other measured outcomes like stiffness, function, WOMAC scores, and impression of change scales demonstrated the superiority of the FX006, especially until week eighth. Authors found a reduction by eightfold of CS peak plasma levels. $^{57}$

A subsequent investigation attempted to determine the optimal dosage of FX006, they compared three groups (16 $\mathrm{mg}, 32 \mathrm{mg}$, and placebo) during 24 weeks and found that the average daily pain was significative improved by the 32 mg concentration for the first 11-13 weeks but only a small difference was found further than 13 weeks. ${ }^{55}$

There are currently ongoing studies on FX006, some of the preliminary results, suggest that this option might consistently provide 12 weeks of pain relief cost-effectively. But these should be analyzed with caution once the final reports are published. ${ }^{58}$

Some authors also suggest that PLGA might not be the optimal component for the microspheres and indicated that polyester amide (PEA) might have a safer profile and better release of the contained medication. ${ }^{59}$

\section{Non-corticoid interventional therapies}

As an alternative to the IA CS, in the recent years, new products and therapies have been used targeting different factors other than inflammation. Although these products 
are promising, still some research is required to determine their efficacy, applicability, and safety profile.

\section{Viscosupplementation with hyaluronic acid}

Hyaluronic acid (HA), is a natural glycosaminoglycan synthesized by type B synovial cells, chondrocytes, and fibroblasts and secreted into the synovial fluid. It provides viscous lubrication, has shocking absorbing properties and additionally, possible anti-inflammatory and anti-oxidant functions have been described. ${ }^{6,9,11}$ In the osteoarthritic knee the concentration and the molecular weight of the HA decrease considerably, ${ }^{9,11}$ and that is why some proposed to viscosupplement the joint in an attempt to restore the HA benefits. The current evidence regarding efficacy is conflicting ${ }^{6,9,11,60}$ and in result, there is variation regarding recommendations from the societies. The AAOS does not recommend its use, ${ }^{15}$ the ACR has no recommendations about it, ${ }^{14}$ the OARSI has an "uncertain recommendation," ${ }^{13}$ and a recent European consensus stated that HA was well tolerated and effective for low and moderate grade OA. ${ }^{61}$ Lastly, this treatment might be more effective in patients with higher levels of knee pain, younger and with lower KL score. ${ }^{60}$

\section{Regenerative medicine}

Aiming to stop and revert the degeneration associated with OA, IA injections of autologous conditioned serum (ACS), platelet rich plasma (PRP), and mesenchymal stem cell (MSC) have been tested..$^{9,11,62,63}$ Their mechanisms of action is reduction of inflammatory reactions mediated by cytokines, and the induction of anabolism and chondrocyte differentiation via growth factors and stem cells contained in it. These methods are promising and some studies have reported them to be safe, well tolerated and, in some cases, superior to IA placebo and HA in terms of pain relief and knee function. ${ }^{911,62,63}$ This is still a developing field and more research is required in order to define and standardize the optimal retrieval, storage, and preparation methods of these products.

\section{Discussion}

Osteoarthritis is a complex and multifactorial condition of the joints, affecting mainly the knees. Multiple hypotheses have been proposed but still there is not a clear etiology or understanding of its natural course. Based on those hypotheses, a wide variety of treatments have been developed and tested, some more successful than others, but ultimately all of them are aimed to decrease pain, increase function, and delay the necessity for a surgical joint replacement. All the current guidelines agree that water or land-based exercise should be attempted first for symptom control, slowly escalating towards the other therapies such as topical or oral medications. If they are not effective, then a patient can receive IA therapies, which seem to have a certain degree of benefit over the oral therapies with some contribution of the placebo effect. Among those therapies, one of the most studied has been IA CS, but it seems that the current data might not be clear given that efforts to elucidate the exact mechanism of action, analgesic efficacy, indication, and safety profile are still ongoing. Recent papers have not been able to provide a robust and clear answer on using IR CS by patients. Some authors have mentioned that the presence of joint effusion, synovial membrane thickness, high BMI, psychological factors, and knee tenderness could be an indicator, but there is no conclusive data on this..$^{31,39-47}$ Perhaps white blood cells counts in the synovial fluid and low degree of radiographical changes on the KL score might be related to a better response, but it is not a definite answer. Part of the conflicting data is because of the high variability of the design of the studies that make them hard to be compared. Nowadays with the advancements in technology and ultrasound, we should aim to use this option whenever available to increase the rate of adequate IA placement of the injected substance. On October 2017, the FDA approved the extended-release presentation for TA contained in microspheres, called FX006, which theoretically, compared to IR CS, should provide a longer lasting pain relief and less adverse effects given the marked reduction on the serum levels of the CS. ${ }^{64,65}$ Some animal models also showed to be protective of the cartilage structure, and also some first studies have shown some adequate safety profile, but there are still doubts regarding its duration beyond 13 weeks. The truth is that this new presentation of an old medication will require more research to clarify some doubts regarding the indications and magnitude of the benefits of the IR option. But it seems that it might play a role if there is a concern of HPA axis suppression and hyperglycemia given its pharmacodynamic properties.

The regenerative medicine field is developing other nonCS IA therapies, showing promising results, but more knowledge and standardization of their therapies will be required.

\section{Conclusion}

Despite being one of the most studied and more prevalent conditions of our population, knee osteoarthritis still does not have a clear pathophysiology or a single most efficacious intervention to treat the symptoms and degeneration associated. Exercises in early stages are a valuable therapy for these patients and it is recommended by all the medical societies. 
Other non-surgical treatments have variable efficacy and their success will depend on multiple variables (provider, equipment, patient) and their use has to be selected judiciously according to the specific clinical situation.

\section{Author contributions}

All authors contributed to data analysis, drafting and revising the article, gave final approval of the version to be published, and agree to be accountable for all aspects of the work.

\section{Disclosure}

The authors report no conflicts of interest in this work.

\section{References}

1. Robinson WH, Lepus CM, Wang Q, et al. Low-grade inflammation as a key mediator of the pathogenesis of osteoarthritis. Nat Rev Rheumatol. 2016;12(10):580-592.

2. Bannuru RR, Schmid CH, Kent DM, Vaysbrot EE, Wong JB, Mcalindon TE. Comparative effectiveness of pharmacologic interventions for knee osteoarthritis: a systematic review and network meta-analysis. Ann Intern Med. 2015;162(1):46-54.

3. Nelson AE, Allen KD, Golightly YM, Goode AP, Jordan JM. A systematic review of recommendations and guidelines for the management of osteoarthritis: The chronic osteoarthritis management initiative of the U.S bone and joint initiative. Semin Arthritis Rheum. 2014;43(6):701-712.

4. da Costa BR, Hari R, Jüni P. Intra-articular Corticosteroids for Osteoarthritis of the Knee. JAMA. 2016;316(24):2671-2672.

5. Jordan JM, Helmick CG, Renner JB, et al. Prevalence of knee symptoms and radiographic and symptomatic knee osteoarthritis in African Americans and Caucasians: the Johnston County Osteoarthritis Project. J Rheumatol. 2007;34(1):172-180.

6. Sharma V, Anuvat K, John L, Davis M. Scientific American Pain Management -Arthritis of the knee. Decker: Pain related disease states; 2017.

7. Richebé P, Capdevila X, Rivat C. Persistent Postsurgical Pain: Pathophysiology and Preventative Pharmacologic Considerations. Anesthesiology. 2018.

8. Kellgren JH, Lawrence JS. Radiological assessment of osteo-arthrosis. Ann Rheum Dis. 1957;16(4):494-502.

9. Ayhan E, Kesmezacar H, Akgun I. Intraarticular injections (corticosteroid, hyaluronic acid, platelet rich plasma) for the knee osteoarthritis. World J Orthop. 2014;5(3):351-361.

10. Dulay GS, Cooper C, Dennison EM. Knee pain, knee injury, knee osteoarthritis \& work. Best Pract Res Clin Rheumatol. 2015;29(3):454-461.

11. Richards MM, Maxwell JS, Weng L, Angelos MG, Golzarian J. Intraarticular treatment of knee osteoarthritis: from anti-inflammatories to products of regenerative medicine. Phys Sportsmed.2016;44(2):101-108.

12. Sellam J, Berenbaum F. The role of synovitis in pathophysiology and clinical symptoms of osteoarthritis. Nat Rev Rheumatol. 2010;6(11):625-635.

13. Mcalindon TE, Bannuru RR, Sullivan MC, et al. OARSI guidelines for the non-surgical management of knee osteoarthritis. Osteoarthritis Cartilage. 2014;22(3):363-388.

14. Hochberg MC, Altman RD, April KT, et al. American College of Rheumatology 2012 recommendations for the use of nonpharmacologic and pharmacologic therapies in osteoarthritis of the hand, hip, and knee. Arthritis Care Res. 2012;64(4):465-474

15. Jevsevar DS. Treatment of osteoarthritis of the knee: evidence-based guideline, 2nd edition. J Am Acad Orthop Surg. 2013;21(9):571-576.

16. Esser S, Bailey A. Effects of exercise and physical activity on knee osteoarthritis. Curr Pain Headache Rep. 2011;15(6):423-430.
17. Tanaka R, Ozawa J, Kito N, Moriyama H. Efficacy of strengthening or aerobic exercise on pain relief in people with knee osteoarthritis: a systematic review and meta-analysis of randomized controlled trials. Clin Rehabil. 2013;27(12):1059-1071.

18. Bennell KL, Hinman RS. A review of the clinical evidence for exercise in osteoarthritis of the hip and knee. J Sci Med Sport. 2011;14(1):4-9.

19. Beckwée D, Vaes P, Cnudde M, Swinnen E, Bautmans I. Osteoarthritis of the knee: why does exercise work? A qualitative study of the literature. Ageing Res Rev. 2013;12(1):226-236.

20. Morrison JB. The mechanics of the knee joint in relation to normal walking. $J$ Biomech. 1970;3(1):51-61.

21. Messier SP, Gutekunst DJ, Davis C, Devita P. Weight loss reduces kneejoint loads in overweight and obese older adults with knee osteoarthritis. Arthritis Rheum. 2005;52(7):2026-2032.

22. Felson DT, Zhang Y, Anthony JM, Naimark A, Anderson JJ. Weight loss reduces the risk for symptomatic knee osteoarthritis in women. The Framingham Study. Ann Intern Med. 1992;116(7):535-539.

23. Christensen R, Astrup A, Bliddal H. Weight loss: the treatment of choice for knee osteoarthritis? A randomized trial. Osteoarthritis Cartilage. 2005;13(1):20-27.

24. Lin J, Zhang W, Jones A, Doherty M. Efficacy of topical non-steroidal anti-inflammatory drugs in the treatment of osteoarthritis: meta-analysis of randomised controlled trials. BMJ. 2004;329(7461):324.

25. Smith SR, Deshpande BR, Collins JE, Katz JN, Losina E. Comparative pain reduction of oral non-steroidal anti-inflammatory drugs and opioids for knee osteoarthritis: systematic analytic review. Osteoarthritis Cartilage. 2016;24(6):962-972.

26. Krebs EE, Gravely A, Nugent S, et al. Effect of Opioid vs Nonopioid Medications on Pain-Related Function in Patients With Chronic Back Pain or Hip or Knee Osteoarthritis Pain: The SPACE Randomized Clinical Trial. JAMA. 2018;319(9):872-882.

27. Cepeda MS, Camargo F, Zea C, Valencia L. Tramadol for osteoarthritis: a systematic review and metaanalysis. J Rheumatol. 2007;34(3):543-555.

28. WHO. WHO Expert Committee on Drug Dependence, Thirty-fourth report. Geneva: World Health Organisation. 2006.

29. Wang ZY, Shi SY, Li SJ, et al. Efficacy and Safety of Duloxetine on Osteoarthritis Knee Pain: A Meta-Analysis of Randomized Controlled Trials. Pain Med. 2015;16(7):1373-1385.

30. Citrome L, Weiss-Citrome A. A systematic review of duloxetine for osteoarthritic pain: what is the number needed to treat, number needed to harm, and likelihood to be helped or harmed? Postgrad Med. 2012;124(1):83-93.

31. Bellamy N, Campbell J, Robinson V, Gee T, Bourne R, Wells G. Intraarticular corticosteroid for treatment of osteoarthritis of the knee. Cochrane Database Syst Rev. 2006;2(2):CD005328.

32. Arroll B, Goodyear-Smith F. Corticosteroid injections for osteoarthritis of the knee: meta-analysis. BMJ. 2004;328(7444):869.

33. Hirsch G, Kitas G, Klocke R. Intra-articular corticosteroid injection in osteoarthritis of the knee and hip: factors predicting pain relief--a systematic review. Semin Arthritis Rheum. 2013;42(5):451-473.

34. Buyuk AF, Kilinc E, Camurcu IY, Camur S, Ucpunar H, Kara A. Compared efficacy of intra-articular injection of methylprednisolone and triamcinolone. Acta Ortop Bras. 2017;25(5):206-208.

35. Law TY, Nguyen C, Frank RM, Rosas S, Mccormick F. Current concepts on the use of corticosteroid injections for knee osteoarthritis. Phys Sportsmed. 2015;43(3):269-273.

36. Yavuz U, Sökücü S, Albayrak A, Oztürk K. Efficacy comparisons of the intraarticular steroidal agents in the patients with knee osteoarthritis. Rheumatol Int. 2012;32(11):3391-3396.

37. Pyne D, Ioannou Y, Mootoo R, Bhanji A. Intra-articular steroids in knee osteoarthritis: a comparative study of triamcinolone hexacetonide and methylprednisolone acetate. Clin Rheumatol. 2004;23(2):116-120.

38. Lomonte AB, de Morais MG, de Carvalho LO, Zerbini CA. Efficacy of Triamcinolone Hexacetonide versus Methylprednisolone Acetate Intraarticular Injections in Knee Osteoarthritis: A Randomized, Doubleblinded, 24-week Study. J Rheumatol. 2015;42(9):1677-1684. 
39. Conaghan P, D'Agostino MA, Ravaud P, et al. EULAR report on the use of ultrasonography in painful knee osteoarthritis. Part 2: exploring decision rules for clinical utility. Ann Rheum Dis. 2005;64(12):1710-1714.

40. Pendleton A, Millar A, O'Kane D, Wright GD, Taggart AJ. Can sonography be used to predict the response to intra-articular corticosteroid injection in primary osteoarthritis of the knee? Scand J Rheumatol. 2008;37(5):395-397.

41. Chao J, Wu C, Sun B, et al. Inflammatory characteristics on ultrasound predict poorer longterm response to intraarticular corticosteroid injections in knee osteoarthritis. $J$ Rheumatol. 2010;37(3):650-655.

42. Dieppe PA, Sathapatayavongs B, Jones HE, Bacon PA, Ring EF. Intra-articular steroids in osteoarthritis. Rheumatol Rehabil. 1980;19(4):212-217.

43. McCabe PS, Parkes MJ, Maricar N, et al. Brief Report: Synovial Fluid White Blood Cell Count in Knee Osteoarthritis: Association With Structural Findings and Treatment Response. Arthritis Rheumatol. 2017;69(1): 103-107.

44. Jones A, Doherty M. Intra-articular corticosteroids are effective in osteoarthritis but there are no clinical predictors of response. Ann Rheum Dis. 1996;55(11):829-832.

45. Arden NK, Reading IC, Jordan KM, et al. A randomised controlled trial of tidal irrigation vs corticosteroid injection in knee osteoarthritis: the KIVIS Study. Osteoarthritis Cartilage. 2008;16(6):733-739.

46. Raynauld JP, Buckland-Wright C, Ward R, et al. Safety and efficacy of long-term intraarticular steroid injections in osteoarthritis of the knee: a randomized, double-blind, placebo-controlled trial. Arthritis Rheum. 2003;48(2):370-377.

47. Maricar N, Callaghan MJ, Felson DT, O’Neill TW, Oâ€тMneill TW. Predictors of response to intra-articular steroid injections in knee osteoarthritis--a systematic review. Rheumatology. 2013;52(6):1022-1032.

48. Cunnington J, Marshall N, Hide G, et al. A randomized, double-blind, controlled study of ultrasound-guided corticosteroid injection into the joint of patients with inflammatory arthritis. Arthritis Rheum. 2010;62(7):1862-1869.

49. Park Y, Lee SC, Nam HS, Lee J, Nam SH. Comparison of sonographically guided intra-articular injections at 3 different sites of the knee. J Ultrasound Med. 2011;30(12):1669-1676.

50. Berkoff DJ, Miller LE, Block JE. Clinical utility of ultrasound guidance for intra-articular knee injections: a review. Clin Interv Aging. 2012;7:89-95.

51. Mcalindon TE, Lavalley MP, Harvey WF, et al. Effect of Intra-articular Triamcinolone vs Saline on Knee Cartilage Volume and Pain in Patients With Knee Osteoarthritis: A Randomized Clinical Trial. JAMA. 2017;317(19):1967-1975.

52. Suntiparpluacha M, Tammachote N, Tammachote R. Triamcinolone acetonide reduces viability, induces oxidative stress, and alters gene expressions of human chondrocytes. Eur Rev Med Pharmacol Sci. 2016;20(23):4985-4992.
53. Brazilian Medical Association, Silvinato A, Bernardo WM. Inflammatory arthritis or osteoarthritis of the knee - Efficacy of intra-joint infiltration of methylprednisolone acetate versus triamcinolone acetonide or triamcinolone hexacetonide. Rev Assoc Med Bras. 2017;63(10):827-836.

54. Kumar A, Bendele AM, Blanks RC, Bodick N. Sustained efficacy of a single intra-articular dose of FX006 in a rat model of repeated localized knee arthritis. Osteoarthritis Cartilage. 2015;23(1):151-160.

55. Conaghan PG, Cohen SB, Berenbaum F, Lufkin J, Johnson JR, Bodick N. Brief Report: A Phase IIb Trial of a Novel Extended-Release Microsphere Formulation of Triamcinolone Acetonide for Intraarticular Injection in Knee Osteoarthritis. Arthritis Rheumatol. 2018;70(2):204-211.

56. Kraus VB, Conaghan PG, Aazami HA, et al. Synovial and systemic pharmacokinetics (PK) of triamcinolone acetonide (TA) following intra-articular (IA) injection of an extended-release microsphere-based formulation (FX006) or standard crystalline suspension in patients with knee osteoarthritis (OA. Osteoarthritis Cartilage. 2018;26(1):34-42.

57. Bodick N, Lufkin J, Willwerth C, et al. An intra-articular, extendedrelease formulation of triamcinolone acetonide prolongs and amplifies analgesic effect in patients with osteoarthritis of the knee: a randomized clinical trial. J Bone Joint Surg Am. 2015;97(11):877-888.

58. Conaghan PG, Berenbaum F, Kraus VB, Johnson J, Kelley S. Updating the Knee Osteoarthritis Intra-Articular Corticosteroid Meta-Analysis with Two Large Trials of Extended-Release Triamcinolone Acetonide (FX006) Versus Placebo [abstract]. Arthritis Rheumatol. 2017;69(Suppl 10).

59. Rudnik-Jansen I, Colen S, Berard J, et al. Prolonged inhibition of inflammation in osteoarthritis by triamcinolone acetonide released from a polyester amide microsphere platform. $J$ Control Release. 2017;253:64-72.

60. Pelletier JP, Raynauld JP, Abram F, Dorais M, Delorme P, MartelPelletier J. Exploring determinants predicting response to intra-articular hyaluronic acid treatment in symptomatic knee osteoarthritis: 9-year follow-up data from the Osteoarthritis Initiative. Arthritis Res Ther. 2018;20(1):40.

61. Henrotin Y, Raman R, Richette P, et al. Consensus statement on viscosupplementation with hyaluronic acid for the management of osteoarthritis. Semin Arthritis Rheum. 2015;45(2):140-149.

62. Wehling P, Evans C, Wehling J, Maixner W. Effectiveness of intraarticular therapies in osteoarthritis: a literature review. Ther Adv Musculoskelet Dis. 2017;9(8):183-196.

63. Shahid M, Kundra R. Platelet-rich plasma (PRP) for knee disorders. EFORT Open Rev. 2017;2(1):28-34.

64. US Food and Drug Adminsitraction. FDA approved drug products. Available from: https://www.accessdata.fda.gov/scripts/cder/daf/ index.cfm? event $=$ overview. process $\&$ ApplNo $=208845$. Accessed September 27, 2018.

65. Flexion Therapeutics, Inc. Highlights of prescribing information. Available from: https://www.accessdata.fda.gov/drugsatfda_docs/ label/2017/208845s000lbl.pdf. Accessed September 27, 2018.
Journal of Pain Research

\section{Publish your work in this journal}

The Journal of Pain Research is an international, peer reviewed, open access, online journal that welcomes laboratory and clinical findings in the fields of pain research and the prevention and management of pain. Original research, reviews, symposium reports, hypothesis formation and commentaries are all considered for publication.

\section{Dovepress}

The manuscript management system is completely online and includes a very quick and fair peer-review system, which is all easy to use. Visit http://www.dovepress.com/testimonials.php to read real quotes from published authors. 